\title{
Transcriptome response of high- and low-light-adapted Prochlorococcus strains to changing iron availability
}

\author{
Anne W Thompson ${ }^{1}$, Katherine Huang ${ }^{1}$, Mak A Saito ${ }^{2}$ and Sallie W Chisholm ${ }^{1,3}$ \\ ${ }^{1}$ MIT Department of Civil and Environmental Engineering, Cambridge, MA, USA; ${ }^{2}$ Department of \\ Marine Chemistry and Geochemistry, Woods Hole Oceanographic Institution, Woods Hole, MA, USA \\ and ${ }^{3}$ MIT Department of Biology, Cambridge, MA, USA
}

\begin{abstract}
Prochlorococcus contributes significantly to ocean primary productivity. The link between primary productivity and iron in specific ocean regions is well established and iron limitation of Prochlorococcus cell division rates in these regions has been shown. However, the extent of ecotypic variation in iron metabolism among Prochlorococcus and the molecular basis for differences is not understood. Here, we examine the growth and transcriptional response of Prochlorococcus strains, MED4 and MIT9313, to changing iron concentrations. During steady state, MIT9313 sustains growth at an order-of-magnitude lower iron concentration than MED4. To explore this difference, we measured the whole-genome transcriptional response of each strain to abrupt iron starvation and rescue. Only four of the 1159 orthologs of MED4 and MIT9313 were differentially expressed in response to iron in both strains. However, in each strain, the expression of over a hundred additional genes changed, many of which are in labile genomic regions, suggesting a role for lateral gene transfer in establishing diversity of iron metabolism among Prochlorococcus. Furthermore, we found that MED4 lacks three genes near the iron-deficiency-induced gene (idiA) that are present and induced by iron stress in MIT9313. These genes are interesting targets for studying the adaptation of natural Prochlorococcus assemblages to local iron conditions as they show more diversity than other genomic regions in environmental metagenomic databases.
\end{abstract} The ISME Journal (2011) 5, 1580-1594; doi:10.1038/ismej.2011.49; published online 12 May 2011 Subject Category: microbial population and community ecology

Keywords: cyanobacteria; iron; transcriptome

\section{Introduction}

The marine cyanobacterium Prochlorococcus is the most abundant photosynthetic cell in the ocean and an important biogeochemical agent (Partensky et al., 1999). Specific environmental parameters, such as light, temperature, phosphorus, nitrogen, cobalt and copper, contribute to the diversity of Prochlorococcus, shaping its distribution and contribution to marine primary productivity. Iron is required for photosynthesis and limits primary productivity in specific ocean regions (Moore et al., 2004; Boyd et al., 2007), hence may be another an important factor in Prochlorococcus ecology. Evidence suggesting this is the limitation of Prochlorococcus cell division rates by iron in the equatorial Pacific (Mann

Correspondence: MA Saito, Department of Marine Chemistry and Geochemistry, Woods Hole Oceanographic Institution, Woods Hole, MA, USA or SW Chisholm, MIT Department of Civil and Environmental Engineering, 15 Vassar Street, Cambridge, MA 02139, USA.

E-mail: msaito@whoi.edu or chisholm@mit.edu

Received 13 October 2010; revised 10 March 2011; accepted 24 March 2011; published online 12 May 2011 and Chisholm, 2000) and variations in the abundance of Prochlorococcus iron-related genes between oceans (Rusch et al., 2010).

Induction of iron stress is a useful approach towards understanding iron metabolism. At the physiological level, loss of chlorophyll (chlorosis) (Öquist, 1971, 1974), reductions in iron quota and diminished cell volume are common iron-stress responses in cyanobacteria and other phototrophs (Sunda and Huntsman, 1995, 1997; Berman-Frank et al., 2001). At the molecular level, diverse phototrophs upregulate the iron-free electron transfer gene, flavodoxin (isiB), and downregulate the ironrequiring electron transfer gene, ferredoxin (petF), possibly reducing iron quota or redirecting iron to other cellular processes (Erdner and Anderson, 1999; McKay et al., 1999). This expression pattern was shown in Prochlorococcus MED4, SS120 and MIT9313 (Bibby et al., 2003). The same study also revealed that when iron-starved, MIT9313's PSI complex associates with the chlorophyll-binding accessory protein PcbB. In contrast, a similar protein associates with SS120's PSI complex under ironreplete and iron-starved conditions, whereas neither 
condition induces such a change in MED4. These results suggest variability in the iron-stress response of Prochlorococcus strains and invite further study.

Comparative genomics provide additional insights into iron metabolism and ecotypic diversity regarding iron. The Prochlorococcus core genome (genes shared by 12 Prochlorococcus isolates-Kettler et al. (2007) and MIT9202 (this study)) contains numerous iron-related genes. In addition to the aforementioned $i s i B$ and petF, the core genome contains several $\mathrm{Fe}-\mathrm{S}$ proteins and ferredoxins, the iron storage molecule ferritin ( $f t n)$ and two ferric uptake regulator (fur) genes. Individual genomes vary in the numbers of each iron-related core gene they contain, possibly leading to distinct physiologies.

For iron transport, idiA (futA/afuA), futB and futC, homologous to components of a periplasmic binding protein-dependent $\mathrm{Fe}^{3+} \mathrm{ABC}$ transporter (Webb et al., 2001), are in the core genome. Various components of other iron transport systems (and other iron-related genes) exist in the Prochlorococcus flexible genomes (genes not shared by all Prochlorococcus genomes). Yet, a complete iron transport system has not yet been recognized in Prochlorococcus, or any marine picocyanobacteria (Webb et al., 2001; Kettler et al., 2007; Hopkinson and Morel, 2009). Thus, it remains unclear as to which iron species (that is, free or ligand-bound) are available to Prochlorococcus, how they acquire it and if differences exist among ecotypes.

Here, we examine the response of Prochlorococcus to iron with the aim of beginning to understand how iron influences Prochlorococcus ecology. To this end, we investigated Prochlorococcus ecotypes MED4 and MIT9313 (Rocap et al., 2003), to tease out iron responses that are general to, or variable among, Prochlorococcus ecotypes. These ecotypes differ in several ways, possibly relevant to their iron metabolisms, including cell size, light physiology, $\mathrm{N}$ metabolism, origin of isolation and gene content (Table 1). We first tested the strains' steady-state growth rates over ranges of precisely controlled iron concentrations to see if they differed in the iron required for growth. Then, we used short-term microarray experiments to identify iron-stress and recovery-responsive transcripts and ask how similar these ecotypes are in their transcriptional response to iron. Finally, we explored a set of particularly interesting iron-stress-induced genes in environmental metagenomic databases to understand their distribution among wild Prochlorococcus populations and potential role in adaptation to local iron regimens.

\section{Methods}

Culture conditions

Prochlorococcus MED4ax and MIT9313ax were grown in PRO99 (Moore et al., 2007) modified for trace-metal clean work through microwave sterilization of seawater, increased EDTA $(11.7 \mu \mathrm{M})$, Chelex100 treatment of major nutrients (Biorad, Hercules, CA, USA) and soaking polycarbonate culture vessels

Table 1 Properties of MED4 and MIT9313 with potential relevance to iron metabolism

\begin{tabular}{|c|c|c|c|}
\hline & MED4 & MIT9313 & Pro. core \\
\hline \multicolumn{4}{|l|}{ Origin of isolation $^{\mathrm{a}}$} \\
\hline Isolation site & Mediterranean & Gulf Stream & - \\
\hline Isolation depth & Surface $(5 \mathrm{~m})$ & Deep $(135 \mathrm{~m})$ & - \\
\hline \multicolumn{4}{|l|}{ Selected iron-related genes ${ }^{\mathrm{a}, \mathrm{b}, \mathrm{c}}$} \\
\hline Ferritin-iron storage & 1 & 2 & 1 \\
\hline Flavodoxin (isiB)-iron-free electron transfer & 1 & 1 & 1 \\
\hline Ferredoxin ( $p e t F$ and others)-iron-requiring electron transfer & 6 & 7 & 3 \\
\hline idiA/afuA-putative iron $\mathrm{ABC}$ transporter, substrate binding protein & 1 & 1 & 1 \\
\hline futB-putative iron $\mathrm{ABC}$ transporter, permease component & 1 & 1 & 1 \\
\hline fut $C / s f u C-\mathrm{ABC}$ transporter, ATP binding component, possibly iron transporter & 1 & 1 & 1 \\
\hline fur-ferric uptake regulator & 2 & 3 & 2 \\
\hline \multicolumn{4}{|l|}{ Cell physiology } \\
\hline Cell size (diameter) & $0.5-0.7 \mu \mathrm{m}^{\mathrm{d}, \mathrm{e}}$ & $0.8-1.2 \mu \mathrm{m}^{\mathrm{e}}$ & - \\
\hline Light adaptation $^{\mathrm{f}}$ & High light & Low light & - \\
\hline Nitrogen sources utilized ${ }^{\mathrm{g}}$ & $\mathrm{NH}_{4}$, urea & $\mathrm{NH}_{4}$, urea, nitrite & - \\
\hline Copper tolerance $^{\mathrm{h}}$ & Higher & Lower & - \\
\hline
\end{tabular}

For each iron-related gene listed, the number of orthologs present in each genome is shown, as well as the number of orthologs present in the Prochlorococcus (Pro.) core genome (that is, genes shared by all 13 sequenced Prochlorococcus).

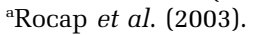

${ }^{b}$ MicrobesOnline (http://www.microbesonline.org/) (Dehal et al., 2010).

cProPortal (http://www.proportal.mit.edu/).

${ }^{\mathrm{d}}$ Morel et al. (1993).

eTing et al. (2007).

${ }^{\mathrm{f}}$ Moore and Chisholm (1999).

goore et al. (2002).

${ }^{\mathrm{h}}$ Mann et al. (2002). 
in $0.1 \%$ Citranox (Alconox, White Plains, NY, USA), 10\% Baker Instra-analyzed HCl (Mallinckrodt Baker, Phillpsburg, NJ, USA) and $\mathrm{pH}_{2} \cdot \mathrm{H}_{2} \mathrm{O}$ for $24 \mathrm{~h}$ each (Keller et al., 1988; Price et al., 1988; Saito et al., 2002). EDTA-buffered media provided chemostatlike conditions by buffering $>99 \%$ of the iron and maintaining a small defined $\mathrm{Fe}^{\prime}$ (dissolved inorganic iron species) concentration throughout the experiment (Sunda et al., 2005). These cultures are chemostat-like conditions because dissociation of the Fe-EDTA complex continually replenishes $\mathrm{Fe}^{\prime}$ throughout the growth curve. Thus, $\mathrm{Fe}^{\prime}$ is not depleted from the media as is typical for batch growth limited by nutrients like $\mathrm{N}$ or $\mathrm{P}$. The ratio of $\mathrm{Fe}^{\prime}$ to $\mathrm{Fe}_{\text {total }}$ used was 0.039 , using the empirical estimates by Sunda and Huntsman (2003) at $10 \mu \mathrm{M}$ EDTA, consistent with the approximately orderof-magnitude lower ratio found at $100 \mu \mathrm{M}$ EDTA as used for eukaryotic phytoplankton iron studies (Sunda and Huntsman, 1995).

For steady-state growth experiments, we chose an irradiance of $20 \mu \mathrm{Em}^{-2} \mathrm{~s}^{-1}$ (continuous, $25^{\circ} \mathrm{C}$ ), representing 16 and $40 \%$ of the light required for MED4 and MIT9313 maximum growth rates, respectively (Moore and Chisholm, 1999). This irradiance was useful for three reasons: first, because photochemical reactions strongly influence $\mathrm{Fe}^{\prime}$ (Sunda and Huntsman, 2003), using a single irradiance allowed a consistent range of $\mathrm{Fe}^{\prime}$ concentrations in the media, enabling strain-to-strain comparisons. Second, at $20 \mu \mathrm{Em}^{-2} \mathrm{~s}^{-1}$, MED4 and MIT9313 grew at similar rates when nutrient replete. This was important as specific growth rate, steady-state iron uptake rates and iron quota are interrelated (Sunda and Huntsman, 1997), and we aimed to isolate the effects of iron uptake and quota differences on growth rate. Thirdly, from a practical perspective, growth at submaximal irradiances facilitates experimental work due to higher pigment-per-cell and sensitivity for bulk fluorescence and flow cytometry. To initiate steady-state experiments, mid-log phase iron-replete cultures were centrifuged (8500 r.p.m., $10 \mathrm{~min}$ ), rinsed twice with sterile seawater and inoculated in duplicate at added $\mathrm{Fe}_{\text {total }}$ concentrations of $0,0.00003,0.0001,0.000567,0.001,0.003$, $0.01,0.1$ and $1 \mu \mathrm{M}$, resulting in added $\mathrm{Fe}^{\prime}$ concentrations of $0 \mathrm{nM}, 0.0012 \mathrm{nM}, 0.0039 \mathrm{nM}, 0.0221 \mathrm{nM}$, $0.039 \mathrm{nM}, \quad 0.12 \mathrm{nM}, \quad 0.39 \mathrm{nM}, \quad 3.9 \mathrm{nM}$ and $39 \mathrm{nM}$, respectively, based on the chemical equilibrium with EDTA described above. Cultures were transferred at mid-log phase until growth rates reached steady state.

For microarray experiments, where we aimed to measure gene expression in response to abrupt changes in iron, rather than compare cells in steady-state growth at precise iron concentrations, we grew MED4 at $27 \mu \mathrm{Em}^{-2} \mathrm{~s}^{-1}$ (continuous, $21^{\circ} \mathrm{C}$ ) (chosen to match other experiments-Martiny et al. (2006) and Steglich et al. (2006)) and MIT9313 at $20 \mu \mathrm{E} \mathrm{m}^{-2} \mathrm{~s}^{-1}$ (continuous, $25^{\circ} \mathrm{C}$ ), in iron-replete $(1 \mu \mathrm{M})$ media prepared as above. To induce iron stress, triplicate cultures were centrifuged, washed (as above), divided and re-suspended in either ironreplete $(1 \mu \mathrm{M} \mathrm{Fe})$ or no added-iron media. RNA and cell number samples were collected (as in Lindell et al., 2007) at $0 \mathrm{~h}, 12 \mathrm{~h}, 24 \mathrm{~h}, 48 \mathrm{~h}$ and $70 \mathrm{~h}$ (MED4) and $0 \mathrm{~h}, 16 \mathrm{~h}, 28 \mathrm{~h}, 53 \mathrm{~h}$ and $72 \mathrm{~h}$ (MIT9313) with iron addition to no added-iron cultures to replete levels at $49 \mathrm{~h}$ (MED4) and $54 \mathrm{~h}$ (MIT9313). Additional cell number samples were collected at selected time points.

We used an Influx flow cytometer (Becton Dickinson, Franklin Lakes, NJ, USA) to measure cell numbers for growth-rate calculations and determination of relative cell size and chlorophyllper-cell (Olson et al., 1990a,b), measuring a minimum of 10000 cells per sample. Relative cell size and chlorophyll per cell were approximated by normalizing forward-angle light scatter and red fluorescence per cell, respectively, to $2 \mu \mathrm{m}$ diameter Fluoresbrite beads (Polysciences Inc., Warrington, PA, USA).

\section{RNA preparation}

MED4 and MIT9313 RNA was extracted using the mirVana miRNA kit (Ambion, Austin, TX, USA) as in Lindell et al. (2007) with lysozyme added to MIT9313 samples (Tolonen et al., 2006) for better lysis. DNA was removed using Turbo DNase (Ambion) as in Lindell et al. (2007). Owing to low yield, DNase-treated MIT9313 RNA was concentrated using Micron Y-30 columns (Millipore, Billerica, MA, USA) and then amplified using the Message Amp TM II-Bacteria Prokaryotic RNA Amplification Kit (Ambion) following the manufacturer's protocol.

\section{Array normalization and analysis}

Custom Affymetrix (Santa Clara, CA, USA) cDNA arrays, MD4-9313, were used to measure wholegenome expression with processing and design as in Lindell et al. (2007) for duplicate (MED4 samples) or triplicate (most MIT9313 samples, otherwise duplicate). Normalization methods, implemented in Matlab (The Mathworks Inc., Natick, MA, USA), followed by Choe et al. (2005) with robust multichip average were used to normalize background signal between arrays and lowess normalization at the probe-set level to correct influences of expression-signal intensity on fold change.

We made five comparisons to assess the iron stress and rescue response for each strain. We compared no added-iron $(-\mathrm{Fe})$ to iron-replete $(+\mathrm{Fe})$ expression at each of the four iron-stress time points (see above) and report fold change for these as $\log _{2}(-\mathrm{Fe} /+\mathrm{Fe})$. Owing to poor hybridization for a MED4 48-h iron-replete sample, 48-h no added-iron samples were compared with 24-h iron-replete samples. A fifth comparison $(R)$ was made between -Fe cultures before (48-h MED4, 53-h MIT9313) and 
after (70-h MED4, 72-h MIT9313) iron rescue, and for this we report fold change as $\log _{2}$ (after rescue/ before rescue). Bayesian statistical analyses were performed in Cyber-T (Baldi and Long, 2001) and Q-VALUE (Storey and Tibshirani, 2003) was used to calculate false discovery rates ( $q$-value) as in Martiny et al. (2006). Following recommendations of Choe et al. (2005), we chose stringent thresholds and define differentially expressed genes as those with $q$-value less than 0.01 and $\log _{2}$ (fold change) greater than 1 or less than -1 in one or more comparisons (Supplementary Tables S1 and S2). Raw data files and normalized expression levels are available in NCBI's Gene Expression Omnibus (Edgar et al., 2002) and are accessible through GEO Series accession number GSE26533 (http://www. ncbi.nlm.nih.gov/geo/query/acc.cgi?acc $=$ GSExxx).

Hierarchical clustering Cluster-Eisen et al. (1998) was performed with $\log _{2}$ (fold change) for every gene in all comparisons using Complete Linkage Clustering and Correlation (centered) as the similarity metric. TreeView (http://www.rana.lbl. gov/EisenSoftware.htm) was used to visualize and analyze cluster results. Cluster membership is presented in Supplementary Tables S1 and S2 for differentially expressed genes.

Recruitment of Prochlorococcus-like global ocean survey reads to sequenced genomes

We established a collection of Prochlorococcus-like reads from the global ocean survey (GOS) database as in Rusch et al. (2007) using 13 Prochlorococcus genomes (Kettler et al. (2007) and MIT9202 (this study)). We required sequence alignments to Prochlorococcus genomes of at least $50 \%$ of the read's length (after trimming the vectors). As a result, we report 402771 Prochlorococcus-like GOS reads out of the total 9893120 GOS reads. AS9601 best represents Prochlorococcus in the GOS database; thus, this genome was used to assess quantity and diversity of natural Prochlorococcus genes in the idiA region. Similar analyses using MIT9312 and MED4 appear in the Supplementary Materials.

\section{Results and discussion}

Steady-state growth over a range of iron concentrations MED4 and MIT9313 displayed different relationships between steady-state growth rate and iron concentration under the chemostat-like (that is, constant $\mathrm{Fe}^{\prime}$ concentration-see Methods) conditions of metal-ion-buffered media in batch cultures (Sunda et al., 2005). Under these light and temperature conditions, MIT9313 grew at the lower $\mathrm{Fe}^{\prime}$ concentrations of $0.022 \mathrm{nM}$ and $0.004 \mathrm{nM}$, whereas MED4 could not (Figure 1), revealing a large difference in the fitness of these ecotypes at lowiron concentrations.

These results were contrary to expectations based on the smaller size of MED4 relative to MIT9313

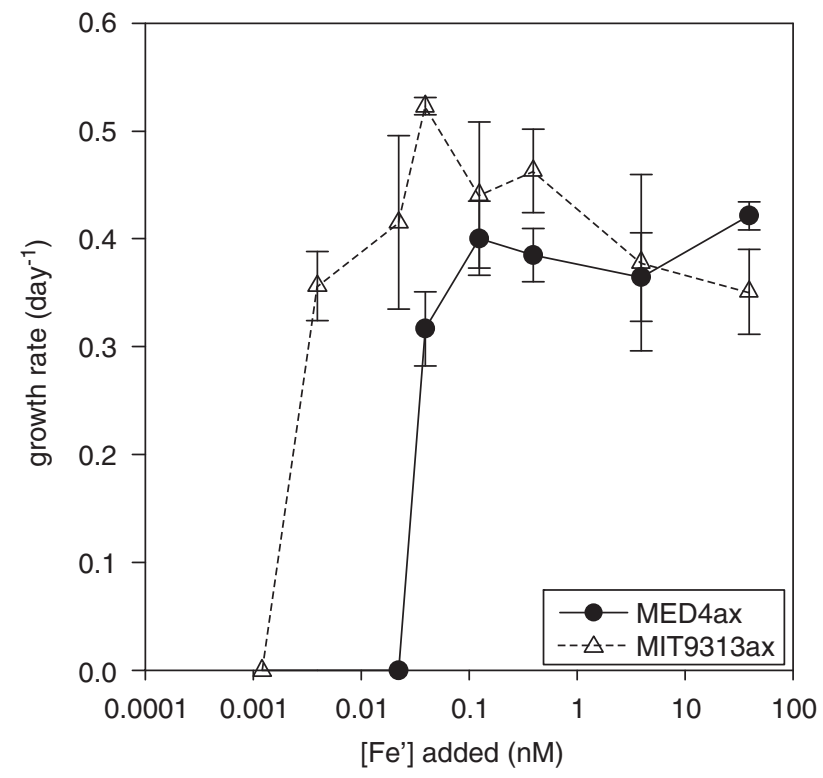

Figure 1 Steady-state growth rates over a range of dissolved iron $\left(\mathrm{Fe}^{\prime}\right)$ concentrations for MED4ax and MIT9313ax grown at $20 \mu \mathrm{E} \mathrm{m}^{-2} \mathrm{~s}^{-1}$.

(Table 1), and the advantage in nutrient acquisition higher surface-area-to-volume ratios are expected to confer. Similarly, from the perspective of light physiology, we imagined that low-light adapted cells (MIT9313) would contain more iron-rich photosystems (Jordan et al., 2001), thus requiring more iron than high-light adapted cells (MED4). However, another important difference between the strains, possibly related to MIT9313's better tolerance of lower iron concentrations than MED4, is the habitat from which they were isolated-MIT9313 from the North-Western Atlantic and MED4 from the Mediterranean Sea (Rocap et al., 2003). Modeling studies (Jickells et al., 2005) and direct $\mathrm{Fe}_{\text {total }}$ measurements of unfiltered samples indicate that concentrations in the Mediterranean Sea (approximately $20-40 \mathrm{nM}$ ) are dramatically higher than that in the North-Western Atlantic (1.5-3.2 nM), where MIT9313 was isolated (Wu and Luther, 1995; Sherrell and Boyle, 1998). Thus, the difference in response of the ecotypes to low iron in culture may originate from the selective pressures imposed by iron availability in the waters where they were isolated-as observed for phosphorus acquisition in Prochlorococcus (Martiny et al., 2006; Coleman and Chisholm, 2010)—through enhanced mechanisms for coping with secondary consequences of iron stress, lower iron quotas or alternative iron acquisition systems. Indeed, Rusch et al. (2010) suggested that low-iron waters select for cells with genomes encoding fewer iron-requiring proteins. Also consistent with our hypothesis is MIT9313's expression of a PSI-associated chlorophyll-binding accessory protein during iron stress, whereas a similar gene and PSI-associated protein are absent in MED4 (Bibby et al., 2003). Finally, it is perhaps worth noting that 

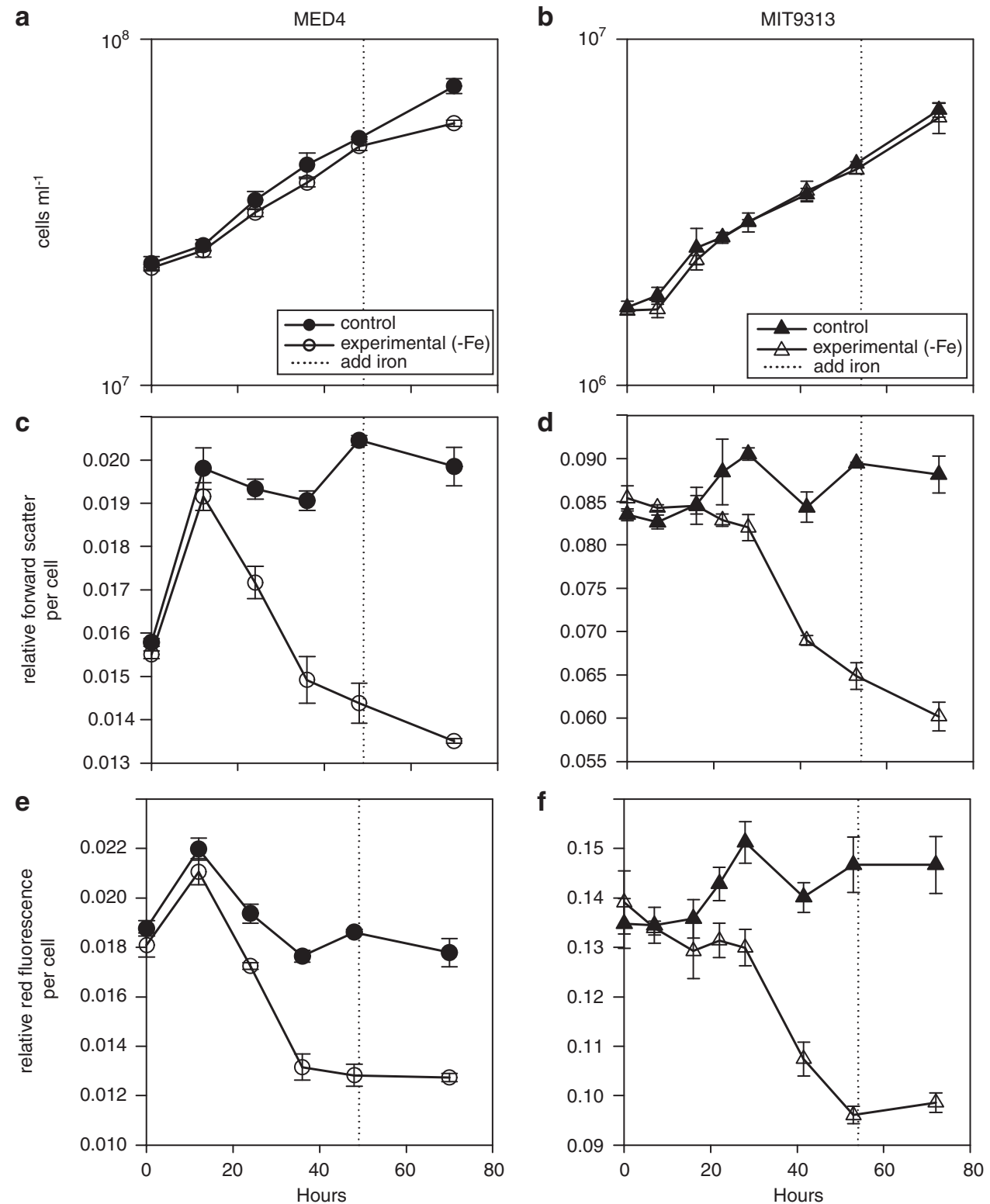

Figure 2 Growth and cell properties of Prochlorococcus MED4 and MIT9313 over a time course of iron deprivation and recovery. The time point at $0 \mathrm{~h}$ was taken immediately after the cells were centrifuged and re-suspended in either $+\mathrm{Fe}$ (control) or $-\mathrm{Fe}$ (experimental) media. (a, b) Changes in cell concentration; (c, d) mean forward angle light scatter (FALS) relative to standard beads; and (e, f) mean red fluorescence relative to standard beads. All points represent the mean of duplicate or triplicate cultures. Dotted line indicates iron addition to the $-\mathrm{Fe}$ treatment.

MIT9313 is more sensitive to copper than MED4 (Mann et al., 2002), which could have its origins in high-affinity metal transporters that allow survival at low metal concentrations.

Physiological response to sudden iron stress and rescue To understand the molecular basis for the difference between MED4 and MIT9313 in steady state at lowiron concentrations and to identify iron-related genes in each genome, we measured whole-genome expression in response to abrupt iron deprivation and rescue in experiments designed to induce stress without large changes in growth rate (as large changes in growth rate could yield gene expression changes not specific to iron). After initiation of short-term iron stress, growth rates of both MED4 and MIT9313 experimental $(-\mathrm{Fe})$ cultures matched the controls $(+\mathrm{Fe})$ for $48 \mathrm{~h}(53 \mathrm{~h}-\mathrm{MIT} 9313)$ at 0.58 and 0.61 per day, respectively (Figures 2a and b). However, relative red fluorescence (proxy for chla) per cell and relative forward-angle light scatter (proxy for cell size) per cell decreased in experimental cultures after $20 \mathrm{~h}$, evidence that iron stress had set in by this time (Figures 2c-f). The decrease in chla is consistent with symptoms of chlorosis 
(Wilhelm, 1995), and the decrease in size is consistent with observations of iron-stressed Prochlorococcus in the field and cultured iron-stressed diatoms and dinoflagellates (Sunda and Huntsman, 1995; Cavender-Bares et al., 1999; Mann and Chisholm, 2000). Upon iron rescue, we observed no significant increase in chla or size in either strain (Figures 2c-f). However, the growth rate of the MED4 experimental culture declined to 0.24 per day, whereas the MIT9313 experimental culture continued to match the control (Figures 2a and b), possibly indicating more severe iron stress in MED4.
Thus, we expect some of the MED4 gene expression changes after rescue $(R)$ to be related to growth rate changes, rather than related directly to iron availability.

Global features of the transcriptional response to sudden iron stress and rescue

Transcription of $6.2 \%$ of MED4 genes and $3.8 \%$ of MIT9313 genes responded to iron stress and rescue (Figures 3a and b). Differential expression was first evident at $12 \mathrm{~h}$ (Figure 3), when changes in
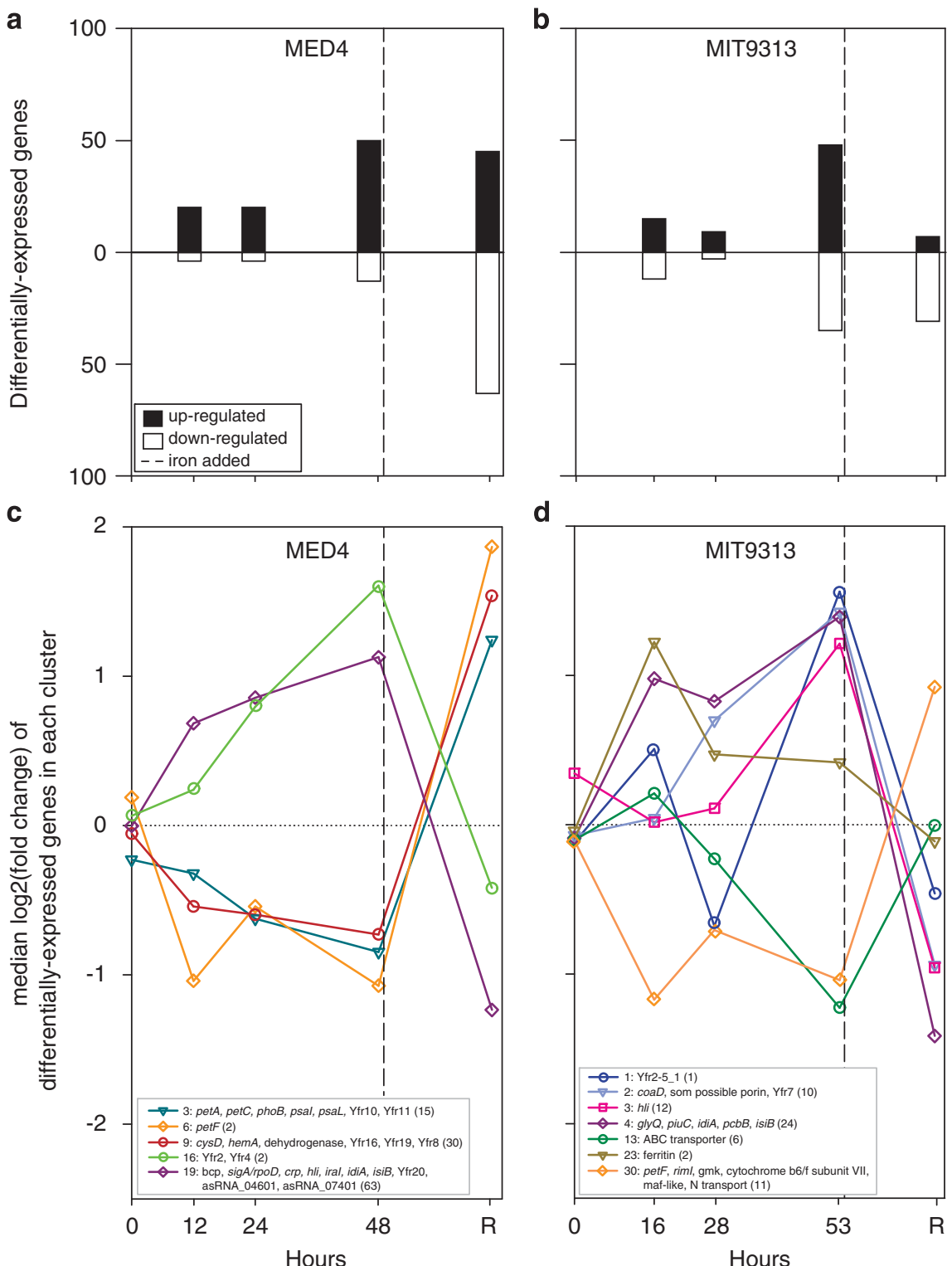

Figure 3 General features of the whole-genome transcription response of MED4 and MIT9313 to iron starvation and rescue. The number of genes that were differentially expressed at each time point for (a) MED4 and (b) MIT9313. Median expression profiles of differentially expressed genes in each hierarchical cluster during iron deprivation and rescue $(R)$ for MED4 (c) and MIT9313 (d). Clusters are listed in the legend and are identified by the cluster number at the beginning of each line. The differentially expressed genes with predicted functions in each cluster are listed with the total number of differentially expressed genes in the cluster given within parentheses at the end of each line. Some clusters contain only differentially expressed genes of unknown function and these are omitted from the figure (for clarity), but presented in Supplementary Tables S1 and S2. 
physiological indicators of iron stress were not yet evident (Figures 2c-f). In addition, gene expression responded dramatically to iron rescue in both strains, although size and chla did not, revealing a temporal divide between recovery from iron stress at the molecular and physiological levels. Hierarchical clustering revealed several clusters containing differentially expressed genes with predicted functions (Figures 3c and d) and some clusters containing only genes of unknown function (Supplementary Tables S1 and S2). In fact, over $60 \%$ of differentially expressed genes in each strain were of unknown function.

Over $80 \%$ of differentially expressed genes were from the flexible genomes (genes not shared by all Prochlorococcus) of MED4 and MIT9313 (Supplementary Table S3-third column), a disproportionally high fraction relative to the proportion of flexible genes in each genome (39.5\%-MED4; $57.9 \%$-MIT9313). In addition, a disproportionate fraction $(67.9 \%$ compared with $22.1 \%$ of MED4's whole genome $-P<0.001$, and $35.3 \%$ compared with $21.2 \%$ of MIT9313's whole genome $-P<0.01$, Fisher's exact test) of the differentially expressed genes reside in genomic islands and/or hypervariable regions (Coleman et al., 2006; Kettler et al., 2007) (Figure 4), and they are almost exclusively flexible genes. It is hypothesized that genomic islands and hypervariable regions are evidence of horizontal gene transfer events in Prochlorococcus and contain genes related to relatively recent adaptations to local environmental conditions
(Coleman et al., 2006; Kettler et al., 2007), which is consistent with our hypothesis that iron-related gene content of these strains is due to the iron regime at their origin of isolation.

MED4 genomic island 5 (ISL5), in particular, was a 'hotspot' for differentially expressed genes in our experiments (Figure 4)-including high-light inducible (hli) genes, and numerous genes of unknown function. Some ISL5 genes respond to P-stress (Martiny et al., 2006), but these are not the same genes-supporting the hypothesis that island genes are involved in specific metabolic pathways rather than a general stress response (Coleman et al., 2006), and that genes in particular genomic islands have diverse functions.

\section{Features of specific differentially expressed genes} MED4-MIT9313 shared genes that respond to iron in both strains. Of the 1159 MED4-MIT9313 shared genes (MED4-MIT9313 bi-directional orthologsSupplementary Table S3), only four were differentially expressed in both strains under our conditions of iron stress and recovery (Figure 5, bold cyan). Two of these, pet $F$ (ferredoxin) and isiB (flavodoxin), are also Prochlorococcus core genes and belong to well-characterized iron-response systems in cyanobacteria and other photosynthetic organisms-see Introduction (Erdner and Anderson, 1999; McKay et al., 1999). As shown previously (Bibby et al., 2003), ferredoxin was downregulated and flavodoxin was upregulated during iron stress in both MED4
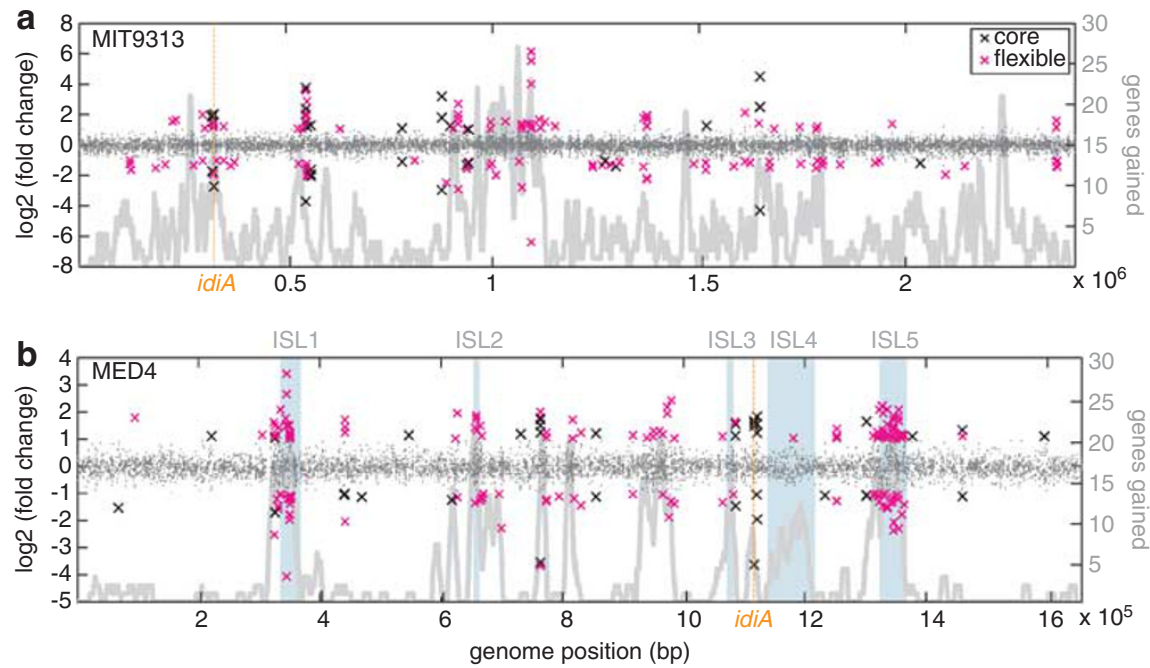

Figure 4 Genome position and fold change of differentially expressed genes for (a) MIT9313 and (b) MED4. Each comparison (see Methods) is represented. Black crosses represent differentially expressed genes that belong to the Prochlorococcus core genome (genes shared by all Prochlorococcus) and magenta crosses represent genes from the flexible genome (genes not shared by all Prochlorococcus). Gray points represent genes that were not significantly differentially expressed. Numbers of genes gained along the genomes (Kettler et al., 2007) are shown in thick gray lines (peaks indicate hypervariable regions) for MED4 and MIT9313. In addition, genomic islands (defined in Coleman et al., 2006) are displayed for MED4 as light blue boxes. Genomic islands have not been defined in MIT9313. For both MED4 and MIT9313, the proportion of differentially expressed genes present in labile regions (genomic islands and/ or hypervariable regions) is greater than the proportion of genes from the whole genome that are present in these labile regions $(P<0.001$, MED4; $P<0.01$, MIT9313, Fisher's exact test). Orange lines mark the location of the idiA region discussed in the text and displayed in Figures 7 and Supplementary Figures S1 and S2. 


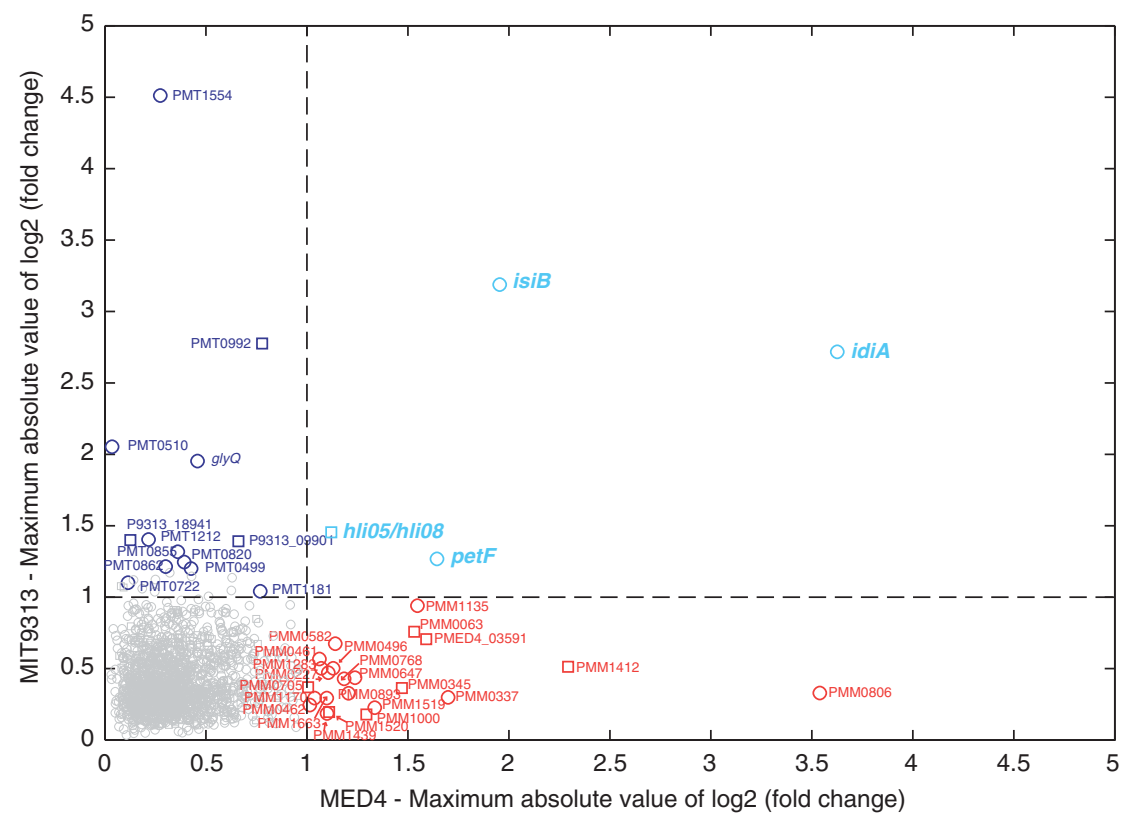

Figure 5 The maximum absolute value of fold-change expression of differentially expressed MED4-MIT9313 shared genes (bi-directional orthologs between MED4 and MIT9313) from all comparisons (see Methods). Directionality of fold change for each gene can be found in Supplementary Tables S1 and S2. Circles indicate genes that are present in the Prochlorococcus core genome and squares indicate genes that are non-core (that is, flexible), but are MED4-MIT9313 shared genes (bi-directional orthologs between MED4 and MIT9313). Dashed lines mark an absolute value $\log _{2}$ (fold change) of 1 (the thresholds for determining significance along with $q$-value-see Methods). Gray symbols: genes that are not differentially expressed. Cyan symbols: genes differentially expressed in both MED4 and MIT9313. Red symbols: genes differentially expressed only in MED4. Blue symbols: genes differentially expressed only in MIT9313. pet $F$ encodes ferredoxin, an iron-requiring electron transfer protein. isiB encodes flavodoxin, an iron-free electron transfer protein known to substitute for petF during iron stress. idiA encodes a possible periplasmic iron-binding protein involved in iron transport. hlio5 and hlios are the names for this hli gene in MED4 and MIT9313, respectively.

and MIT9313, suggesting flexibility in the iron requirements of Prochlorococcus depending on iron availability.

Another MED4-MIT9313 shared gene (although not a Prochlorococcus core gene) differentially expressed in both strains is the hli gene hlio5/hlios (PMM1404/PMT1154), which is upregulated in MED4 during iron stress and downregulated in both strains upon rescue (Supplementary Tables S1 and S2). Although a large number of hli genes were differentially expressed in our experiments (Supplementary Tables S1 and S2), this is the only one that is both shared by, and differentially expressed in, both strains. Hli proteins may have a role in protecting photosystems from oxidative damage, which has been shown to be a consequence of iron stress in cyanobacteria (Latifi et al., 2005) and may be a common feature of the response to changing iron availability in MED4 and MIT9313.

A fourth MED4-MIT9313 shared gene (also a Prochlorococcus core gene) differentially expressed in both strains is the iron-deficiency-induced gene (idiA), homologous to afuA in Synechococcus PCC7942 and idiA in Synechococcus PCC6301 (Michel et al., 1999, 2001; Webb et al., 2001), was upregulated during iron stress, as observed previously (Katoh et al., 2001; Webb et al., 2001; Singh et al., 2003) and downregulated following rescue. IdiA is hypothesized to be a periplasmic iron-binding protein component of an iron ABCtransporter system including an ATP-binding protein (futC) and permease (futB) (Webb et al., 2001), which were not differentially expressed in either Prochlorococcus strain, consistent with their constitutive expression in Synechocystis PCC6083 (Katoh et al., 2001).

Different genes, similar functions. It was surprising that so few MED4-MIT9313 shared genes were commonly differentially expressed by both strains (Figure 5 and Supplementary Tables S1 and S2). However, looking more closely, we found groups of genes (although different in each strain, and including both MED4-MIT9313 shared and non-shared genes) with common functions. Specifically, although PSII (2-3 atoms $\mathrm{Fe}$ ) genes were not downregulated during iron stress in either strain, genes encoding the iron-rich (12 atoms Fe) PSI complex were downregulated in response to iron stress in both strains. Notably, these PSI components-psaM in MIT9313, psaI and psaL in MED4-are transmembrane- $\alpha$ helices that stabilize cofactors of the PSI core antennae system (Jordan et al., 2001). Possibly, during iron stress, the downregulation of these stabilizing factors makes room for other proteins that maintain PSI function, releases iron for other uses and/or precedes downregulation of the major PSI components (such as psaA). Similarly, cytochrome $b 6 / f$ 
complex components were downregulated in both strains, including heme-binding pet $A$ (cytochrome $f$ ) and the Rieske iron-sulfur subunit, petC, in MED4, and the cytochrome $b 6 / f$ complex subunit VII in MIT9313. Thus, both MED4 and MIT9313 may be able to conserve iron by downregulating these ironrequiring proteins. We speculate that differential expression of some, rather than all, components of these complexes under our conditions may be due to different functions, mRNA half-lives and/or protein turnover rates for each (Steglich et al., 2010).

Although essential for homeostasis, iron can trigger production of damaging reactive oxygen species (Latifi et al., 2005). Thus, we expect to find a sophisticated regulatory system for iron uptake, storage and use in Prochlorococcus. Surprisingly, fur-a negative repressor of iron transport and storage genes (Hantke, 2001; Gaballa et al., 2008)— was not differentially expressed in MED4 or MIT9313. In addition to Fur, regulatory RNAs are known to be important in cyanobacterial iron metabolism. In iron-stressed Synechocystis and Anabaena, cis-encoded regulatory RNAs, IsiR and $a$-furA, regulate aspects of photosynthesis and diverse metabolic processes (Massé et al., 2007). In Prochlorococcus, numerous small non-coding RNAs (sRNAs) responded to nitrogen, phage and light stress conditions (Steglich et al., 2008), and one particular sRNA, Yfr1, has been shown to target the transcription of two specific outer membrane proteins (Richter et al., 2010). We observed differential expression of several, albeit different, sRNAs in MED4 and MIT9313 (Supplementary Tables S1 and S2), suggesting that sRNAs are also important regulatory agents for Prochlorococcus iron metabolism. This observation is also consistent with metatranscriptomic data from the Pacific revealing sRNAs flanked by Prochlorococcus iron transport genes (Shi et al., 2009). The differentially expressed sRNAs fall into distinct hierarchical clusters (Supplementary Tables S1 and S2), and some sRNAs, for example Yfr11 and Yfr19, are also controlled by light and phage infection, suggesting a range of target genes and functional roles for sRNAs in Prochlorococcus iron metabolism (Steglich et al., 2008, Richter et al., 2010).

Finally, both strains differentially expressed nitrogen transporters, although the genes are not MED4-MIT9313 shared genes, showing another similarity in the abrupt response to iron of MED4 and MIT9313. In MED4, PMM0370-a putative cyanate transporter-was downregulated following rescue and could signal a transition from the use of a different $\mathrm{N}$ species during iron stress (possibly cyanate) that may require less iron for assimilation. In MIT9313, PMT2240 (formate/nitrite transporter) was downregulated with iron stress. Cyanobacterial nitrite reductases require iron (Luque et al., 1993), and although the MIT9313 nitrite reductase was not differentially expressed, downregulation of the nitrite transporter during iron stress may trigger events that would ultimately lead to this, possibly reducing iron requirement.

Different genes, different functions. In addition to genes differentially expressed by MED4 and MIT9313 that have similar functions despite being different genes, many other genes (both shared and non-shared) were differentially expressed under our conditions of iron stress and recovery (Figure 5 and Supplementary Tables S1 and S2). This set includes MED4-MIT9313 shared genes that were differentially expressed in only one strain and genes not shared by the two strains. Possibly, these genes are important in establishing the different tolerances of MED4 and MIT9313 to low iron (Figure 1).

Numerous MED4-MIT9313 shared genes were differentially expressed only in MIT9313 under our conditions of iron stress. One of the two ferritin (iron storage) genes in MIT9313 (PMT0499), for example, was upregulated $16 \mathrm{~h}$ after iron deprivation, whereas the single ferritin gene in MED4 was not differentially expressed. PMT0862, another MED4-MIT9313 shared gene predicted to encode an $\mathrm{Fe}-\mathrm{S}$ oxidoreductase, was also strongly upregulated in MIT9313 during iron stress, but was unchanged in MED4. The pentapeptide repeat gene, PMT1554, is another interesting case as it was strongly induced in MIT9313 during iron stress, yet not differentially expressed in MED4. Tandemly repeated series of amino acids characterize the pentapeptide repeat protein family, which is well represented in both prokaryotic and eukaryotic genomes, although few are of known function (Vetting et al., 2006). Lastly, the shared gene rimI (PMT0510) encodes a GCN5-related $N$-acetyltransferase protein and was downregulated in MIT9313 during iron stress, but not differentially expressed in MED4.

Conversely, several MED4-MIT9313 shared genes were differentially expressed in MED4, but not MIT9313 under these experimental conditions (Figure 5). Notably, the transcription of hemA (glutamyl-tRNA reductase), of the chlorophyll synthesis pathway, was strongly downregulated in MED4 with iron stress, which is consistent with chlorosis in the iron-stressed cells (Figures $3 \mathrm{e}$ and f). It is unclear as to why hem $A$ was not differentially expressed in MIT9313 where chlorosis was also evident. Another MED4-MIT9313 shared gene, PMM1283, was upregulated during iron stress in MED4, but was unchanged in MIT9313, although it was upregulated under more severe $(120 \mathrm{~h})$ iron stress in MIT9313 in another study (Gómez-Baena et al., 2009). PMM1283 is annotated as an integralmembrane protein interacting with the metalloprotease FtsH (a protein that possibly degrades the D1 protein of PSII during photoinhibition); thus, by association, PMM1283 may be involved in facilitating similar photosystem rearrangements required during iron stress as during photoinhibition (Silva et al., 2003; Bieniossek et al., 2006). Lastly, PMM0345 
(a peroxiredoxin and possible bacterioferritin comigratory protein) is induced in MED4 during iron stress, but not in MIT9313. Both genomes contain two such genes, but only this one is differentially expressed. As bacterioferritins are involved in iron storage, the induction of this gene under iron limitation may indicate changes in iron allocations and storage within MED4 that are distinct from changes facilitated by ferritin, which was upregulated in MIT9313 during iron stress.

PMM0805 and PMT0498 are an intriguing pair of differentially expressed genes as their genomic context is preserved in MED4 and MIT9313, but the genes themselves are not bi-directional orthologs in these genomes (Kettler et al., 2007). These genes are located between a CRP-family bacterial regulatory protein (a shared gene iron induced only in MED4) and ferritin (a shared gene only iron induced in MIT9313), and are close to other iron-related (but not differentially expressed) genes such as futC (ATP-binding component of an iron ABC transporter-present in both genomes), iron transport gene fepC in MED4 and a second copy of ferritin in MIT9313 (PMT0495). Strangely, the iron-stress response of the two genes was different: PMM0805 was upregulated, whereas PMT0498 was downregulated (Supplementary Tables S1 and S2). The origins of this difference are unclear, but could result from the slightly different light and temperature conditions (see Methods) or different degrees of iron stress experienced by MED4 and MIT9313 as a result of their individual iron requirements and different growth conditions. Alternatively, differences in the regulation of genes in this region or functional differences between this pair of genes could explain the different transcriptional responses. Clearly, this genomic region is of great interest regarding Prochlorococcus iron metabolism.

In contrast, several of MED4's differentially expressed genes are absent in MIT9313 (belonging to the non-shared genes). PMM1400 (a redox-related protein with homology to the viral protein hemagglutinin neuraminidase) draws our attention as its expression is highly induced in MED4 during iron stress. PMM1400 is also present in all other HL-adapted and NATL Prochlorococcus genomes and several phage genomes (Sullivan et al., 2005; Kettler et al., 2007). Interestingly, Prochlorococcuslike DNA fragments similar to PMM1400 are sparse in predicted iron-limited regions compared with other ocean regions (Rusch et al., 2010). In addition, although PMM1400 is adjacent to hli genes, it is downregulated during high-light stress, whereas the hlis are upregulated (Steglich et al., 2006). Another MED4 gene of particular interest is a possible $\mathrm{Mn}$ ABC transporter (iral) that was upregulated during iron stress, clustered with idiA and $i s i B$, and is absent in MIT9313. It is located close to one fur gene and other putative Mn transporters supporting a role for this gene in trace-metal metabolism. Manganese is an important element in protecting against reactive oxygen species in other bacteria (Posey and Gherardini, 2000; Daly et al., 2004); thus, it may have a similar role in reacting to oxidative stress in MED4 as a consequence of iron stress.

The MIT9313 genome contains several differentially expressed genes that are not present in MED4 (belonging to the non-shared genes). One notable member of this group is $p c b B$. The association of PcbB with PSI under iron stress has been shown in MIT9313 (Bibby et al., 2003) and we observed similar differential expression (Supplementary Table S2). Hence, it is tempting to speculate that this protein contributes to MIT9313's increased fitness at low-iron concentrations relative to MED4, as it is absent in the latter (Bibby et al., 2003). Possibly, PcbB stabilizes PSI during iron stress allowing continuation of light harvesting, protects PSI from oxidative damage or allows redistribution of iron from PSI during iron stress. Interestingly, $p c b B$ is very similar to the constitutively expressed $p c b A$ genes of MED4 and MIT9313 (Bibby et al., 2003), confirming a diversity of function among this group of similar genes.

Finally, during iron stress MIT9313 upregulated three genes in the idiA region that are missing in MED4. These genes are particularly fascinating in light of MIT9313's survival at lower iron concentrations than MED4 and are discussed in the next section.

The idiA region. Intriguingly, MED4 is missing three genes between idiA and glyQ (glycyl-tRNA synthetase $\alpha$-subunit, iron stress induced in MIT9313 only) that are present in MIT9313. Importantly, these three MIT9313 genes between idiA and glyQ are iron stress induced and so are intriguing in the context of the different abilities of the two strains to grow at low-iron concentrations (Figure 1). The genes include PMT0284 (a possible porin), PMT0285 (a possible peptidase of family M20/M25/M40) and PMT0286 (a putative hydroxylase with homology to the pneumococcal iron uptake gene, piuC).

Excepting MED4, all sequenced Prochlorococcus genomes contain orthologs to the genes between idiA and glyQ in MIT9313 (Figure 6). These genes have also been observed in Prochlorococcus DNA fragments from the Pacific Ocean, and were hypothesized to be involved in iron acquisition based on their proximity to idiA and homology to iron transport genes (Coleman and Chisholm, 2007). PMT0286 (piuC) is homologous to a component of an iron transport system in Streptococcus pneumoniae (Brown et al., 2001; Tai et al., 2003; Ulijasz et al., 2004) and porins (PMT0284) are important molecules in cyanobacteria for small solute uptake through diffusion (Hoiczyk and Hansel, 2000). The upregulation of these genes under iron stress supports the hypothesis that these genes are involved in Prochlorococcus iron metabolism, specifically iron uptake. Possibly, the genes have a 


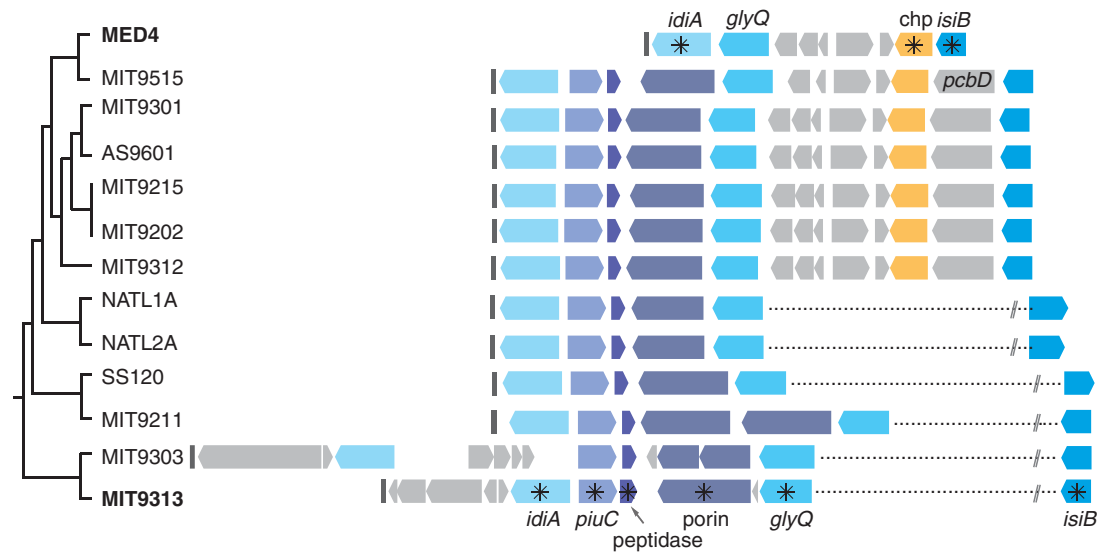

Figure 6 The idiA region of sequenced Prochlorococcus genomes. Genomes are organized vertically by phylogeny (Kettler et al., 2007). Asterisks indicate iron-stress induced transcription. The purple-tinted symbols represent genes not present in MED4 and include piuC (an uncharacterized iron-regulated protein-PMT0286), a possible peptidase (of the M20/M25/M40 family-PMT0285) and som (a possible porin-PMT0284). Blue-tinted symbols represent genes that are present in both MED4 and MIT9313. The yellow symbols represent an iron-induced conserved hypothetical gene (chp) not present in MIT9313. Black boxes represent tRNAs and dotted lines with slashes indicate extensive distances between genes along the genome.

functional role in determining the advantage of MIT9313 over MED4 at lower iron concentrations by allowing more efficient iron transport or providing access to an alternate (that is, not $\mathrm{Fe}^{\prime}$ ) species of iron not available to MED4 (Figure 1).

To assess how well represented these genes are among wild Prochlorococcus, we explored their prevalence in the GOS database, by quantifying reads recruiting to the idiA region of Prochlorococcus AS9601 (a well-represented genome in the GOS database). The abundances of reads recruiting to genes of interest (Figure 7a and Supplementary Figures S1A and S2A for other reference genomes) were similar to those recruiting to nearby genes such as core gene $p s b D$ (photosystem II D2 protein) that we expect to occur in single copy in Prochlorococcus cells, with the notable exception of small island regions where few reads recruited. This suggests that the suite of genes in the idiA region is present in most wild Prochlorococcus cells in the GOS database and that cells like MED4, missing the three genes, are a minority in the waters sampled in GOS-consistent with our understanding of the longitudinal distribution of the MED4 ecotype (Johnson et al., 2006).

However, examination of the similarity of the recruited reads to AS9601 (Figures 7b; Supplementary Figures S1B and S2B for the other reference genomes) revealed an interesting feature: the reads aligning to the genes between glyQ and idiA have low sequence similarity $(70.36 \pm 7.40 \%)$ to the AS9601 genome compared with the average $(86.49 \pm 12.27 \%)$. Analysis of the same region among the genomes of cultured Prochlorococcus isolates revealed similar sequence divergence in this region relative to AS9601 (Supplementary Figure S3). The relatively high sequence diversity in this set of genes, and their location adjacent to a tRNA, suggest that they could be prone to horizontal gene transfer and loss events. The region (Figure 4, orange line) is also identified as a small genomic island, in MED4 and MIT9312 (Coleman et al., 2006), and is marked by a spike in the number of gene gain events (Kettler et al., 2007) (Figure 4b, gray line)—again, consistent with this being a labile region of the genome, and possibly involved in the adaptation of Prochlorococcus to different iron regimens.

\section{Conclusions}

This study used precisely controlled iron concentrations to test the tolerance of two Prochlorococcus ecotypes to low iron availability and whole-genome microarrays to identify genes that respond to abrupt iron stress and rescue. We found that the two closely related ecotypes, MED4 and MIT9313, have dramatically different lower limits with regard to iron concentrations that sustain steady-state growth. This suggests a role for iron in the physiological and genomic differentiation among Prochlorococcus.

Underlying these physiological differences are a number of characteristics at the transcriptome level discovered through imposing abrupt iron stress and recovery: (1) most genes that are differentially expressed in response to iron are in the flexible genomes of MED4 and MIT9313. In fact, only four of the hundreds of genes shared by MED4 and MIT9313 (three of which are also Prochlorococcus core genes) are differentially expressed in both strains; (2) differentially expressed genes are concentrated in labile regions (genomic islands and hypervariable regions) of the genomes; and (3) sequence similarity patterns of idiA-region genes of sequenced genomes and Prochlorococcus DNA fragments from the GOS database may reflect horizontal gene transfer events of genes, possibly related to iron transport. Taken together, these 

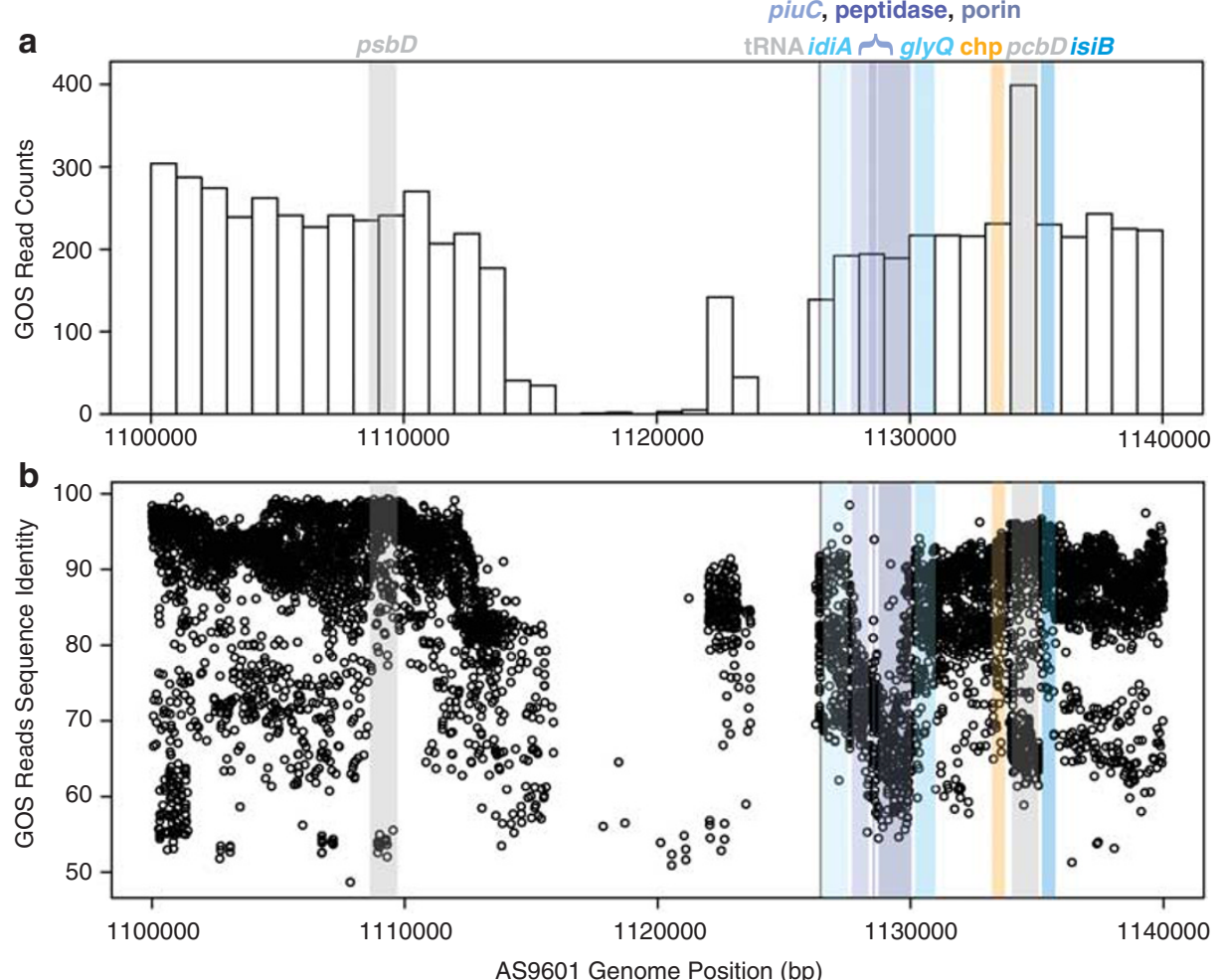

Figure 7 Abundance and diversity of Prochlorococcus-like reads from the global ocean survey (GOS) database in the idiA region. The AS9601 genome best represents Prochlorococcus in the GOS database, and thus is used as a reference genome here. Similar plots with MIT9312 and MED4 are provided in Supplementary Materials (Supplementary Figures S1 and S2). (a) Abundance of recruited Prochlorococcus-like GOS reads aligning to AS9601 and (b) percent similarity of recruited Prochlorococcus-like GOS reads to the AS9601 genome. From left to right, genes of interest are $p s b D$ (a reference core gene encoding the PSII D2 protein), tRNA (black), idiA (cyan), piuC (purple, AS9601_13531), possible peptidase (purple, AS9601_13541), possible porin (purple, AS9601_13551), glyQ (cyan), conserved hypothetical gene (chp-yellow), $p c b D$ (gray)_present in multiple copies in some Prochlorococcus genomes, and isiB (cyan).

observations suggest that adaptation to local iron conditions is a contributor to the diversity among Prochlorococcus and possibly to the success of this group in low-iron regions of ocean.

We speculate that underlying MIT9313's ability to grow at lower iron concentrations than MED4 are three important features: (1) a more efficient iron transport system adapted to low-iron concentrations; (2) a capability to better protect itself from deleterious secondary consequences of iron stress, such as oxidative stress; and (3) a lower cellular iron requirement than MED4. In support of (1) is the ironinduced expression of MIT9313 genes adjacent to idiA (piuC, a possible peptidase, and a possible porin) that are absent in MED4. These genes may enable more efficient iron transport, or provide access to an iron species not accessible to MED4for example, iron bound to ligands. Attribute (2) is supported by the association of a chlorophyllbinding antenna protein (PcbB) - the gene for which is absent in MED4-with PSI during iron stress in MIT9313 (Bibby et al., 2003). We do not have evidence supporting (3), but a recent metagenomic study (Rusch et al., 2010) revealed that Prochlorococcus from lower iron waters contain fewer ironbinding proteins than from higher iron waters, suggesting a possible mechanism through which iron requirements could vary among Prochlorococcus, as we suspect they do between MED4 and MIT9313.

Clearly, the mechanisms that underlie the differential fitness of these two strains at low-iron concentrations are complex as are the fundamental aspects of iron transport and use in Prochlorococcus and marine picocyanobacteria. Furthermore, as cultures have been maintained in high-iron culture media for close to two decades, it will be important to compare our results from cultured strains to the iron requirements and gene expression responses of naturally occurring Prochlorococcus. The results reported here offer more questions than answers, but provide an essential baseline for future studies. In particular, defining the relationship between light availability and iron requirement in Prochlorococcus, identifying a complete iron uptake system and unveiling the function of uncharacterized iron-related genes will be critical for expanding our understanding to a level where a more complete picture could emerge.

\section{Acknowledgements}

We acknowledge Debbie Lindell and the G Church Lab for the design of the MD4-9313 array and thank Claudia 
Steglich, Maureen Coleman, Daniel Sher, Paul Berube, Tyler Goepfert and Erin Bertrand for their involvement in pilot experiments, growth studies, array analysis and interpretation of results. We are also very grateful to Eric Webb for his advice and consult on this project. Funding was provided through the Gordon and Betty Moore Foundation, NSF Biological Oceanography, NSFCMORE and DOE-GTL to SWC. Additional funding was provided through an ONR Young Investigator Award, NSF Chemical Oceanography and NSF Environmental Genomics grants to MAS. We also thank four anonymous reviewers for their insightful comments.

\section{Author contributions}

AWT, SWC and MAS designed experiments; AWT conducted experiments; AWT and $\mathrm{KH}$ analyzed data; $\mathrm{KH}$ provided computational tools and environmental metagenomic analysis; and AWT, SWC and MAS wrote the paper.

\section{References}

Baldi P, Long AD. (2001). A Bayesian framework for the analysis of microarray expression data: regularized $t$-test and statistical inferences of gene changes. Bioinformatics 17: 509-519.

Berman-Frank I, Cullen JT, Shaked Y, Sherrell RM, Falkowski PG. (2001). Iron availability, cellular iron quotas, and nitrogen fixation in Trichodesmium. Limnol Oceanogr 46: 1249-1260.

Bibby TS, Mary I, Nield J, Partensky F, Barber J. (2003). Low-light-adapted Prochlorococcus species possess specific antennae for each photosystem. Nature 424: 1051-1054.

Bieniossek C, Schlach T, Bumann M, Meister M, Meier R, Baumann U. (2006). The molecular architecture of the metalloprotease FtsH. Proc Natl Acad Sci USA 103: 3066-3071.

Boyd PW, Jickells T, Law CS, Blain S, Boyle EA, Buesseler $\mathrm{KO}$ et al. (2007). Mesoscale iron enrichment experiments 1993-2005: synthesis and future directions. Science 315: 612-617.

Brown JS, Gilliland SM, Holden DW. (2001). A Streptococcus pneumoniae pathogenicity island encoding an ABC transporter involved in iron uptake and virulence. Mol Microbiol 40: 572-585.

Cavender-Bares KK, Mann EL, Chisholm SW, Ondrusek ME, Bidigare RR. (1999). Differential response of equatorial Pacific phytoplankton to iron fertilization. Limnol Oceanogr 44: 237-246.

Choe S, Boutros M, Michelson A, Church G, Halfon M. (2005). Preferred analysis methods for Affymetrix GeneChips revealed by a wholly defined control dataset. Genome Biol 6: R16.

Coleman ML, Chisholm SW. (2007). Code and context: prochlorococcus as a model for cross-scale biology. Trends Microbiol 15: 398-407.

Coleman ML, Chisholm SW. (2010). Ecosystem-specific selection pressures revealed through comparative population genomics. Proc Natl Acad Sci USA 107: 18634-18639.

Coleman ML, Sullivan MB, Martiny AC, Steglich C, Barry K, DeLong EF et al. (2006). Genomic Islands and the ecology and evolution of Prochlorococcus. Science 311: 1768-1770.
Daly MJ, Gaidamakova EK, Matrosova VY, Vasilenko A, Zhai M, Venkateswaran A et al. (2004). Accumulation of $\mathrm{Mn}$ (II) in Deinococcus radiodurans facilitates gamma-radiation resistance. Science 306: 1025.

Dehal PS, Joachimiak MP, Price MN, Bates JT, Baumohl JK, Chivian D et al. (2010). MicrobesOnline: an integrated portal for comparative and functional genomics. Nucleic Acids Res 38: D396-D400.

Edgar R, Domrachev M, Lash AE. (2002). Gene Expression Omnibus: NCBI gene expression and hybridization array data repository. Nucleic Acids Res 30: 207-210.

Eisen MB, Spellman PT, Brown PO, Botstein D. (1998). Cluster analysis and display of genome-wide expression patterns. Proc Natl Acad Sci USA 95: 14863-14868.

Erdner DL, Anderson DM. (1999). Ferredoxin and flavodoxin as biochemical indicators of iron limitation during open-ocean iron enrichment. Limnol Oceanogr 44: 1609-1615.

Gaballa A, Antelmann H, Aguilar C, Khakh SK, Song K, Smaldone GT et al. (2008). The Bacillus subtilis ironsparing response is mediated by a Fur-regulated small RNA and three small, basic proteins. Proc Natl Acad Sci 105: 11927-11932.

Gómez-Baena G, Rangel OA, López-Lozano A, GarcíaFernández JM, Diez J. (2009). Stress responses in Prochlorococcus MIT9313 vs SS120 involve differential expression of genes encoding proteases $\mathrm{ClP}, \mathrm{ftsH}$ and Lon. Res Microbiol 160: 567-575.

Hantke K. (2001). Iron and metal regulation in bacteria. Curr Opin Microbiol 4: 172-177.

Hoiczyk E, Hansel A. (2000). Cyanobacterial cell walls: news from an unusual prokaryotic envelope. J Bacteriol 182: 1191-1199.

Hopkinson BM, Morel FMM. (2009). The role of siderophores in iron acquisition by photosynthetic marine microorganisms. Biometals 22: 659-669.

Jickells TD, An ZS, Andersen KK, Baker AR, Bergametti G, Brooks $\mathrm{N}$ et al. (2005). Global iron connections between desert dust, ocean biogeochemistry, and climate. Science 308: 67-71.

Johnson ZI, Zinser ER, Coe AC, McNulty NP, Woodward EMS, Chisholm SW. (2006). Niche partitioning among Prochlorococcus ecotypes along ocean-scale environmental gradients. Science 311: 1737-1740.

Jordan P, Fromme P, Witt HT, Klukas O, Saenger W, Krausz N. (2001). Three-dimensional structure of cyanobacterial photosystem I at $2.5 \AA$ resolution. Nature 411: 909-917.

Katoh H, Hagino N, Grossman AR, Ogawa T. (2001). Genes essential to iron transport in the cyanobacterium Synechocystis sp. strain PCC 6803. J Bacteriol 183: 2779-2784.

Keller MD, Bellows WK, Guillard RL. (1988). Microwave treatment for sterilization of phytoplankton culture media. J Exp Mar Biol 117: 279-283.

Kettler GC, Martiny AC, Huang K, Zucker J, Coleman ML, Rodrigue $S$ et al. (2007). Patterns and implications of gene gain and loss in the evolution of prochlorococcus. PLoS Genet 3: e231.

Latifi A, Jeanjean R, Lemeille S, Havaux M, Zhang C. (2005). Iron starvation leads to oxidative stress in Anabaena sp. strain PCC 7120. J Bacteriol 187: 6596-6598.

Lindell D, Jaffe JD, Coleman ML, Futschik ME, Axmann IM, Rector T et al. (2007). Genome-wide expression dynamics of a marine virus and host reveal features of co-evolution. Nature 449: 83-86. 
Luque I, Flores E, Herrero A. (1993). Nitrite reductase gene fro Synechococcus sp. PCC 7942: homology between cyanobacterial and higher-plant nitrite reductases. Plant Mol Biol 21: 1202-1205.

Mann EL, Ahlgren N, Moffett JW, Chisholm SW. (2002). Copper toxicity and cyanobacteria ecology in the Sargasso Sea. Limnol Oceanogr 47: 976-988.

Mann EL, Chisholm SW. (2000). Iron limits the cell division rate of Prochlorococcus in the eastern equatorial Pacific. Limnol Oceanogr 45: 1067-1076.

Martiny AC, Coleman ML, Chisholm SW. (2006). Phosphate acquisition genes in Prochlorococcus ecotypes: evidence for genome-wide adaptation. Proc Natl Acad Sci 103: 12552-12557.

Massé E, Salvail H, Desnoyers G, Arguin M. (2007). Small RNAs controlling iron metabolism. Curr Opin Microbiol 10: 140-145.

McKay RML, LaRoche J, Yakunin AF, Durnford DG, Geider RJ. (1999). Accumulation of ferredoxin and flavodoxin in a marine diatom in response to Fe. J Phycol 35: 510-519.

Michel K, Krüger F, Pühler A, Pistorius EK. (1999). Molecular characterization of $i d i A$ and adjacent genes in the cyanobacteria Synechcoccus sp. strains PCC 6301 and PCC 7942. Microbiology 145: 1473-1484.

Michel K, Pistorius EK, Golden SS. (2001). Unusual regulatory elements for iron deficiency induction of the idiA Gene of Synechococcus elongatus PCC 7942. I Bacteriol 183: 5015-5024.

Moore JK, Doney SC, Lindsay K. (2004). Upper ocean ecosystem dynamics and iron cycling in a global threedimensional model. Global Biogeochem Cycles 18: GB4028.

Moore LM, Coe AC, Zinser ER, Saito MA, Sullivan MB, Lindell D et al. (2007). Culturing the marine cyanobacterium Prochlorococcus. Limnol Oceanogr Methods 5: 353-362.

Moore LR, Chisholm SW. (1999). Photophysiology of the marine cyanobacterium prochlorococcus: ecotypic differences among cultured isolates. Limnol Oceanogr 44: 628-638.

Moore LR, Post AF, Rocap G, Chisholm SW. (2002). Utilization of different nitrogen sources by the marine cyanobacteria Prochlorococcus and Synechococcus. Limnol Oceanogr 47: 989-996.

Morel A, Ahn Y, Partensky F, Vaulot D, Claustre H. (1993). Prochlorococcus and Synechococcus: a comparative study of their optical properties in relation to their size and pigmentation. J Mar Res 51: 617-649.

Olson RJ, Chisholm SW, Zettler ER, Altabet MA, Dusenberry JA. (1990a). Spatial and temporal distributions of prochlorophyte picoplankton in the North Atlantic Ocean. Deep-Sea Res 37: 1033-1051.

Olson RJ, Chisholm SW, Zettler ER, Armbrust EV. (1990b). Pigments, size, and distribution of Synechoccus in the North Atlantic and Pacific oceans. Limnol Oceanogr 35: 45-58.

Öquist G. (1971). Changes in pigment composition and photosynthesis induced by iron-deficiency in the blue-green alga Anacystis nidulans. Physiol Plant 25: 188-191.

Öquist G. (1974). Iron deficiency in the blue green alga Anacystis nidulans: changes in pigmentation and photosynthesis. Physiol Plant 30: 30-37.

Partensky F, Hess WR, Vaulot D. (1999). Prochlorococcus, a marine photosynthetic prokaryote of global significance. Microbiol Mol Biol Rev 63: 106-127.
Posey JE, Gherardini FC. (2000). Lack of a role for iron in the Lyme disease pathogen. Science 288: 1651.

Price NM, Harrison GI, Hering JG, Hudson RJ, Nirel PMV, Palenik B et al. (1988). Preparation and chemistry of the artificial algal culture medium Aquil. Biol Oceanogr 6: 443-461.

Richter AS, Schleberger C, Backofen R, Steglich C. (2010). Seed-based INTARNA prediction combined with GFPreporter system identifies mRNA targets of the small RNA Yfr1. Bioinformatics 26: 1-5.

Rocap G, Larimer FW, Lamerdin J, Malfatti S, Chain P, Ahlgren NA et al. (2003). Genome divergence in two Prochlorococcus ecotypes reflects oceanic niche differentiation. Nature 424: 1042-1047.

Rusch DB, Halpern AL, Sutton G, Heidelberg KB, Williamson S, Yooseph S et al. (2007). The Sorcerer II Gobal Ocean Sampling expedition: Northwest Atlantic through eastern tropical Pacific. PLoS Biol 5: e77.

Rusch DB, Martiny AC, Dupont CL, Halpern AL, Venter JC. (2010). Characterization of Prochlorococcus clades from iron-depleted oceanic regions. Proc Natl Acad Sci 107: 16184-16189; early edition: 1-6.

Saito MA, Moffett JW, Chisholm SW, Waterbury JB. (2002). Cobalt limitation and uptake in Prochlorococcus. Limnol Oceanogr 47: 1629-1636.

Sherrell RM, Boyle EA. (1998). Zinc, chromium, vanadium and iron in the Mediterranean Sea. Deep-See Res 35: 1319-1334.

Shi Y, Tyson GW, DeLong EF. (2009). Metatranscriptomics reveals unique microbial small RNAs in the ocean's water column. Nature 459: 266-272.

Silva P, Thompson E, Bailey S, Kruse O, Mullineaux CW, Robinson C et al. (2003). FtsH is involved in the early stages of repair of photosystem II in Synechocystis sp PCC 6803. Plant Cell 15: 2152-2164.

Singh AK, McIntyre LM, Sherman LA. (2003). Microarray analysis of the genome-wide response to iron deficiency and iron reconstitution in the cyanobacterium Synechocystis sp. PCC 6803. Plant Physiol 132: 1825-1839.

Steglich C, Futschik M, Rector T, Steen R, Chisholm SW. (2006). Genome-wide analysis of light sensing in Prochlorococcus. J Bacteriol 188: 7796-7806.

Steglich C, Futschik ME, Lindell D, Voss B, Chisholm SW, Hess WR. (2008). The challenge of regulation in a minimal photoautotroph: non-coding RNAs in Prochlorococcus. PLoS Genet 4: e1000173.

Steglich C, Lindell D, Futschik M, Rector T, Steen R, Chisholm SW. (2010). Short RNA half-lives in the slow-growing marine cyanobacterium Prochlorococcus. Genome Biol 11: R54.

Storey JD, Tibshirani R. (2003). Statistical significance for genomewide studies. Proc Natl Acad Sci USA 100: 9440-9445.

Sullivan MB, Coleman ML, Weigele P, Rohwer F, Chisholm SW. (2005). Three Prochlorococcus cyanophage genomes: signature features and ecological interpretations. PLOS Biol 3: 0791-0806.

Sunda W, Huntsman SA. (1995). Iron uptake and growth limitation in oceanic and coastal phytoplankton. Mar Chem 50: 189-206.

Sunda W, Huntsman SA. (1997). Interrelated influence of iron, light and cell size on marine phytoplankton growth. Nature 390: 389-392.

Sunda W, Huntsman SA. (2003). Effect of pH, light, and temperature on Fe-EDTA chelation and Fe hydrolysis in seawater. Mar Chem 84: 35-47. 
Sunda W, Price NM, Morel FMM. (2005). Trace metal ion buffers and their use in culture studies. In: Anderson $\mathrm{R}$ (ed). Algal Culturing Techniques. Academic Press: Burlington, MA. pp 35-63.

Tai SS, Yu C, Lee JK. (2003). A solute binding protein of Streptococcus pneumoniae iron transport. FEMS Microbiol Lett 220: 303-308.

Ting CS, Hsieh C, Sundararaman S, Mannella C, Marko M. (2007). Cryo-electron tomography reveals the comparative three-dimensional architecture of Prochlorococcus, a globally important marine cyanobacterium. J Bacteriol 189: 4485-4493.

Tolonen AC, Aach J, Lindell D, Johnson ZI, Rector T, Steen R et al. (2006). Global gene expression of Prochlorococcus ecotypes in response to changes in nitrogen availability. Mol Syst Biol 2: 53.

Ulijasz AT, Andes DR, Glasner JD, Weisblum B. (2004). Regulation of iron transport in Streptococcus pneumoniae by RitR, and orphan response regulator. J Bacteriol 186: 8123-8136.

Vetting MW, Hegde SS, Fajardo JE, Fiser A, Roderick SL, Takiff HE et al. (2006). Pentapeptide repeat proteins. Biochemistry 45: 1-10.

Webb EA, Moffett JW, Waterbury JB. (2001). Iron stress in open-ocean cyanobacteria (Synechococcus, Trichodesmium, and Crocosphaera spp.): identification of the IdiA protein. Appl Environ Microbiol 67: 5444-5452.

Wilhelm SW. (1995). Ecology of iron-limited cyanobacteria: a review of physiological responses and implications for aquatic systems. Aquat Microb Ecol 9: 295-303.

Wu J, Luther GW. (1995). Complexation of Fe(III) by natural organic ligands in the Northwest Atlantic Ocean by a competitive ligand equilibration method and kinetic approach. Mar Chem 50: 159-177.

Supplementary Information accompanies the paper on The ISME Journal website (http://www.nature.com/ismej) 